\title{
Adaptive Innovation and a MOODLE-based VLE to Support a Fully Online MSc Business Information Technology (BIT) at the University of East London (UEL)
}

\author{
Anastasis Petrou \\ School of Computing, Information Technology, and Engineering \\ (CITE), University of East London, London, United Kingdom
}

\author{
t.petrou@uel.ac.uk
}

\begin{abstract}
This paper examines approaches to innovation as theoretical background to systems development life cycle (SDLC) practices employed during open source software development using MOODLE to implement a new virtual learning environment (VLE) for an e-learning project at the University of East London (UEL). The School of Computing, Information Technology and Engineering (CITE) and UELconnect, UEL's distance learning arm, have worked together to develop and implement the new VLE. The paper argues that the emerging Adaptive Innovation Approach, when used as a broad SDLC framework and inclusive of the respective work done by Eric von Hippel on Distributed Innovation and Henry Chesbrough on Open Innovation, can support a practitioneroriented and a user-centred SDLC to better account for new cultural necessities and new economic realities dominating our dynamic global era. The paper takes a closer look at the development of UEL's MOODLE-based VLE for its adaptive innovation qualities and offers various lessons from the validation of a Fully Online MSc Business Information Technology (BIT) that was developed alongside with the VLE. Finally, the paper offers some additional observations from testing MOODLE's eMail Block installed in the new VLE to accommodate internal communication for the newly validated MSc.
\end{abstract}

Keywords: SDLC, Innovation, Distributed Innovation, Open Innovation, Adaptive Innovation, MOODLE, VLE

\section{Introduction}

Manufacturer-driven innovation initiatives have exclusively shaped the development of products, processes, and technologies during the $19^{\text {th }}$ Century and for the better part of the $20^{\text {th }}$ Century. This innovation exclusivity has meant that manufacturers (and many software companies early

Material published as part of this publication, either on-line or in print, is copyrighted by the Informing Science Institute. Permission to make digital or paper copy of part or all of these works for personal or classroom use is granted without fee provided that the copies are not made or distributed for profit or commercial advantage AND that copies 1) bear this notice in full and 2) give the full citation on the first page. It is permissible to abstract these works so long as credit is given. To copy in all other cases or to republish or to post on a server or to redistribute to lists requires specific permission and payment of a fee. Contact Publisher@,InformingScience.org to request redistribution permission. on) analysed, designed, and delivered products to market without input or feedback during the development process from technology users.

However, since the 1950s user involvement in the systems development life cycle (SDLC) has been paramount for success and acceptance of technologyrelated products in global markets. Such user involvement represents a major 
cultural turn in terms of how innovation is integrated into and transforms technology-related products which make up the fabric of all market sectors, the educational sector included.

This paper examines approaches to innovation as a background to SDLC practices employed during open source software development using MOODLE to implement a new virtual learning environment (VLE) for an e-learning project at the University of East London (UEL). The School of Computing, Information Technology and Engineering (CITE) and UELconnect, UEL's distance learning arm, worked together to develop and implement the new VLE.

The paper argues that the emerging Adaptive Innovation Approach, when used as a broad SDLC framework and inclusive of the respective work done by von Hippel $(1998,2007)$ on Distributed Innovation and Chesbrough (2003) on Open Innovation, can support a practitioner-oriented and a user-centred SDLC to better account for new cultural necessities and new economic realities dominating our dynamic global era. von Hippel's approach includes a focus on user-centred innovation. However, von Hippel still stresses reliance on traditional rent producing innovations and transaction costs, although he does criticise manufacturer-driven innovation dominance and does recognise the importance of lead users in innovative activities.

On the other hand, Chesbrough (2003) offers a terrific discussion on open innovation and intellectual property, but his resource-based view is still traditional in its reliance on rational choice and economic rationality theory. Both approaches are focused on organisations and business theory and strategy. There is no utilisation of culture and cultural theories in either approach as backdrop for understanding what users in all types of organisations (for profit and not for profit) and walks of life want and need from technologies and why all users innovate at varying degrees in how they use technology for everyday tasks. Finally both von Hippel and Chesbrough rely on somewhat traditional economic rationality accounts of strategy which tend to lack a psychological, social and cultural content and bend.

The Adaptive Innovation Approach builds on the contributions made by von Hippel and Chesbrough to our understanding of the theory and practice of innovation and highlights even more the contributions made by practitioners and everyday users in the development of innovative capacity in all types of organisations. The adaptive / evolutionary approach is implicit in the work of von Hippel and Chesbrough, but never clearly brought out and isolated for discussion and additional development until now that our economic and cultural realities require such further development.

This paper takes a closer look at the development of UEL's MOODLE-based VLE for its adaptive innovation qualities and offers various lessons from the validation of a Fully Online MSc Business Information Technology (BIT) which was developed alongside with the VLE. Finally, the paper offers some additional observations from testing MOODLE's eMail Block installed in the new VLE to accommodate internal communication for the newly validated MSc.

\section{Approaches to Innovation: The Case for Adaptive Innovation}

\section{Traditional Approach: Manufacturer-driven (Software Company-Dictated)}

Professionals in the Information, Computing, and Technology fields use the systems development life cycle (SDLC) construct as a reference to the stages involved in the development of systems, computer-based ones in particular. 
The traditional approach to systems development invokes a specific set of phases or stages and sequence of steps for the SDLC exemplified in the Waterfall Model.

In his original Waterfall Model, Royce (1970) offers the following phases:

1. Requirements Specification (system / software)

2. Preliminary Design

3. Analysis

4. Program Design

5. Coding

6. Testing

7. Operation

Many criticisms exist of the Waterfall Model, although it continues to be a dominant systems development model. Patterson (2006) states three problems with the Waterfall Model of relevance to this paper:

One problem is the duration of the phases: although phases tend to begin in the logically predictable sequence, in reality they never end. The products from each phase, if perfect, would indeed bring an end of the phase. A second problem is the suggestion that only one phase is active at one time. A third problem is the possible claim that separate organizations may have complete control of the project at different times in the development process without the loss of continuity. (p. 4)

Unpredictability in terms of duration and effectiveness of stages has impacted the success of many a systems development project. Failure in systems development can frequently be traced back to the lack of project management effectiveness in terms of iteration within stages to gain the best possible outcome before moving on to the next stage.

The third problem identified above is an interesting one not only in terms of the charges it levies against continuity but also in terms of the possibilities for innovation from division of work among different organisations. Rianto, Laksani and Prihadyanti (2007) provide evidence that vertical specialisation is a driver of technological and innovation capability building in Indonesia's automotive industry. In this instance, the authors discuss vertical specialisation as the decision by multinational firms to "outsource input processing to their foreign affiliates, thereby creating global production networks in which each actor is vertically specialised" (p. 1).

During vertical specialisation arrangements companies in Country B (i.e., Indonesia) receive specific instructions from a manufacturer in Country A in terms of production of specific parts or entire products. As Rianto, Laksani and Prihadyanti (2007) discuss, technology transfer happens during vertical specialisation arrangements. Furthermore, manufacturers rely on partner companies to closely monitor their production processes in order to comply with initial product specifications.

While products must be developed according to specifications, the process and stages involved in production can be modified and invented anew to meet quality and time delivery standards. "Innovation capability of automotive component companies in Indonesia is provoked by the presence of vertical specialisation" (Rianto et al., 2007, p. 13).

While partner companies in Indonesia's automotive components sector were required to comply with specifications and delivery schedules, these same partner companies found it necessary to orchestrate their own process innovations to complete their contracts with manufacturers. Innovation was not a necessary ingredient in how the vertical specialisation arrangement was set up. And yet, innovation at the local level was indispensable to successful completion of the contracts and impacted how products were completed to comply with initial manufacturer requirements. 


\section{Eric von Hippel's Approach: Distributed Innovation - The Importance of User-driven and Practice-centred Innovation}

Eric von Hippel's Distributed Innovation $(1998,2007)$ construct strongly emphasises the position that the manufacturer is never the only source of innovation. Furthermore, in all of his work, von Hippel stressed the key assumption that profit seeking is the predominant motivation for innovators. But he did bring attention to other issues which highlight the diversity of innovation sources and his writings are food for thought about the strategic role of technology in today's society.

In his 1988 book on "The Sources of Innovation," von Hippel provides a series of studies and other evidence to clearly support a great diversity in terms of innovation sources. Among other innovation sources he names users and suppliers, but not practitioners per say.

In the above book, as well as in other publications, including his 2007 publication about "Horizontal innovation networks - by and for users," he argues that economic rents are not the only reasons for innovation, but certainly innovation is very much driven by a quest for higher rents. Horizontal innovation networks enable "each using entity, whether an individual or a corporation, to develop exactly what it wants rather than being restricted to available marketplace choices or relying on a specific manufacturer to act as its (often very imperfect) agent" (von Hippel, 2007, p. 294).

A further differentiation is needed of contributions to innovation of not only users in an economic context, but also of users in various professional domains, including those in education. User contributions to innovation can come from users anywhere, including contributions from lead users in professional, non-programming and non-manufacturer contexts. von Hippel's "horizontal" element in innovation must also highlight work done by technology users in education who are not primarily motivated by economic gain although who would not shy away from developing an economically viable innovation. This group of users, such as academics, information services, and technology support professionals, are frequently interested in empowering other users (sometimes other lead users and learners) to do their work, study, and learn using computer systems and/or a virtual learning environment (VLE) as the case continues to be with the development of the MOODLE-based VLE at UEL. In this paper, the Adaptive Innovation Approach, among other things, stresses the role that practitioners and academic professionals play in innovation.

\section{Henry Chesbrough's Approach: Open Innovation - The Reality of Multiple Sources for Innovation and the Trouble with the Resource-Based View}

Both von Hippel and Chesbrough accept a necessary diversity in terms of innovation sources. However, their assumptions, evidence employed and use of theory to frame their arguments are significantly different.

Chesbrough's Open Innovation (2003) construct encapsulates the need for companies to look for interesting and innovative ideas both internally and externally. In this instance, the manufacturer and / or any organisation involved in the production of goods and services must undertake environmental scanning to find profitable inventions that can be taken to market in the form of new or innovative products. These ideas or innovations can come from inside or outside a specific organisation.

The focus in Chesbrough is on business strategy and in finding ways to promote the organisation's competitiveness through improvements in organisational capability.

Subsequently, organisational theory and the relationship of the organisation to innovation, intellectual property and resources are the background to Chesbrough's discussions and research. 
While he is interested in profit making from innovating inventions into marketable products, he is broadly interested in ways to use external knowledge and he accounts for issues of intellectual property. Once again, the Adaptive Innovation Approach is mindful of Chesbrough's contributions and extends his work in other areas, but also gives it a cultural, non-economic rationality twist.

\section{Adaptive / Formative Innovation}

Many a factor shapes innovation's adaptive dimensions. External support and entrepreneur's inclination are two such factors in an adaptive innovation model provided by Husti (2009, p. 145).

Under external support social, political, and economic issues as well as competition-compulsion, technology push, and demand pull are listed. Under the entrepreneur's inclination motivation, knowledge, experiences, information and possibilities are listed.

The Husti (2009) adaptive innovation model is about agriculture and technology, but the lessons offered are important for any sector. Innovation may not be the result of exploitation of one single invention or one single area of technological change. Rather innovation can be the outcome of a complex evolutionary process which involves building relationships with partners, suppliers, and customers and capitalising on small and also broader changes.

Herein, adaptive innovation is conceptualised as an incremental, evolutionary, and creative response to what has been happening during the past 2-3 decades in terms of changes and interruptions in a currently hypercompetitive business environment. D'Aveni, Canger, and Doyle (1993) best described the hypercompetitive nature of business in the $20^{\text {th }}$ century when they stated,

We have seen giants of American industry, such as General Motors and IBM, shaken to their cores. Their competitive advantages, once considered unassailable, have been ripped and torn in the fierce winds of competition. Technological wonders appear overnight. Aggressive global competitors arrive on the scene. Organisations are re-structured. Markets appear and fade. The weathered rule books and generic strategies once used to plot our strategies no longer work in this environment. (p. 45)

D’Aveni (1994) in his new 7S Framework includes the following seven strategies:

1. Superior stakeholder satisfaction

2. Strategic soothsaying

3. Speed

4. Surprise

5. Shifting rules of competition

6. Signaling strategic intent

7. Simultaneous and sequential strategic thrusts

D'Aveni's 7S Framework is important as background to a discussion about adaptive innovative as it highlights conditions which require adaptive innovation approaches in business at the present time. D'Aveni's work brings discussions about technology, change and adaptive strategies together.

Technology change theories must address specifically the current hypercompetitive environment and to stress the need for an adaptive point of view to frame best practices for innovation. Adaptive innovation best practices must recognise and support:

"Variation - differences between firms in their economic performance traceable to the differences in their technological and organisational capabilities.

Selection - the competitive process by which the different technologies capabilities acquire level of economic significance over time. 
Generation - bring about creative capacity or innovative variation." (Theories of Technological Change, n.d.).

Adaptive innovation, although much needed in our current volatile and hypercompetitive environment, is not new as a concept. Galambos (1992) details the use of innovation at the turn of the $20^{\text {th }}$ century for the Bell Telephone Company under the leadership of Theodore N. Vail. Galambos (1992) discusses how Vail's management style evolved to culminate around 1908 to an "innovation mode ... [which] ...was essentially an "adaptive" strategy of eliminating uncertainty in the process of producing equipment and providing services" (p. 106).

Veil's adaptive innovation mode was reshaped later on to include a "formative" dimension that focused on the introduction of new technologies and ways to shift production functions. But what should be noted here according to Galambos was that Veil relied decisively both on internal and external sources of innovation. Initially Veil assumed innovations would originate from outside Bell. The latter assumption was based on the reality that initially Bell had an underdeveloped internal Research and Development arm. In subsequent years, the development of an internal bureau of research and information prompted Veil to extol Bell's ability to generate its own fundamental innovation and ability to grow indefinitely in terms of size, efficiency, and usefulness (Galambos, 1992, p. 107).

\section{Adaptive Innovation and the Fully Online MSc BIT Project at the University of East London (UEL) - A New "Corporate" Virtual Learning Environment}

During February 2009 the Fully Online MSc Business Information Technology (BIT) project was initiated in the School of Computing, information Technology and Engineering (CITE). The project's main aim has been to develop a new MSc BIT to be delivered online. In order for the MSc to be delivered online, the School forged a partnership with UEL's distance learning arm, UELconnect. However, before the MSc could be delivered online, it needed to be validated. The validation process required a validation document, a student handbook, and a programme specification among other documents.

To develop the needed documents and to also decide on a virtual learning environment, a project development team was put together. At the initial stages of the project, the team included a project manager, a learning designer, a project officer, and a learning technologist from UELconnect. An academic project manager was assigned to the team from CITE. The Associate Dean for Academics at CITE has been overseeing the project since its inception.

The purpose of the MSc was / is to attract fully employed IT professionals who wanted to top-up their BIT skills. In the early stages of the project, the critical decision was made to put in place an innovative virtual learning environment (VLE) to accommodate high levels of interaction and knowledge exchange online. MOODLE was selected as a VLE capable of supporting needed high levels of interaction, web visibility, online social networking, and knowledge exchange. The facts that MOODLE is an open source VLE and can be had for free online were also strong factors in the decision making process.

Furthermore, the development team's decision to select MOODLE as a VLE was strongly influenced by two other related factors. First, MOODLE can be configured to allow users to contribute to online content, and, second, MOODLE enables online tutors / teachers to modify the VLE and its learning pathways by adding communication tools to enhance interaction and engagement over time. Additional comments about this user-centred flexibility are offered below in the discussion section. 
The Fully Online MSc BIT was granted preliminary validation on 18 November 2009 with full validation extended in early January 2010 after three validation conditions were satisfied. On the year anniversary of the programme's validation, UELconnect and CITE will need to report on how well the new VLE has supported delivery of the new fully online MSc BIT. The latter is standard procedure for newly validated programmes. The current version of the UEL MOODLE VLE is available at http://vle.uelconnect.org.uk/.

\section{Discussion}

\section{Adaptive Innovation \& the Fully Online MSc BIT at UEL and Considerations for the Development of a VLE}

The development team's decision to select MOODLE as the VLE for the fully online MSc BIT was guided by variation, selection, and generation discussed earlier in Adaptive / Formative Innovation.

At the present time, UEL uses UELPlus as the established corporate VLE. As such, UELPlus relies on its vendor (manufacturer, a software company) for major changes and innovation, although some local innovations in terms of use of the VLE can be had.

However, for all intentions and purposes UELPlus as a VLE is an example of the manufacturerled or software company-dictated type of innovation in software applications discussed by von Hippel (2007) and Chesbrough (2003). Subsequently, users of the UELPlus VLE rely on the software company's desire to generate new "rents" or new profit levels from new developments in order to benefit from software re-designs.

On the other hand, use of MOODLE at UEL goes beyond the software's existing levels of development to include innovative benefits for and by users. Not only can all developers download and use MOODLE for free, but they can also make changes or customise it to serve local learning needs, which are now doing at UEL.

Adaptive innovation best practices must support variation, selection, and generation in relation to the new technology use. True enough MOODLE is used in many other Universities. However, further development of MOODLE at UEL is progressing differently and it is varied enough from other University locations so that at the end a well-differentiated product can be had. As at the present time we are at the very beginning stages of further development of MOODLE, it is hard to predict how and/or what the MOODLE VLE at UEL will look like in a year's time. Most of the development team's time between March 2009 and January 2010 was devoted in presenting a prototype of MOODLE to be used for validation of our first fully online MSc Business Information Technology. However, enough development and testing have been accomplished and these will be presented below.

In terms of selection, which is the second adaptive innovation best practice presented in the section Adaptive / Formative Innovation, MOODLE offers UEL and its online programmes different technological capabilities for engagement and social networking. The latter are not fully and immediately available to UELPlus users. These capabilities can help CITE and the University employ a sound web-based strategy for reaching out to more markets.

Finally, in terms of generation, which is the third adaptive innovation best practice presented in the section Adaptive / Formative Innovation, MOODLE does offer UEL e-learning functionalities which can promote creative capacity and innovative variation. Online Tutors can be given authorisation as Teachers to load new communication tools and new resources. 
Teachers can also be authorised to add self-assessments and quiz tools very easily in all areas of a module. In addition, students can access the "MyMOODLE" page to customise it for their own needs, study habits and to load resources for personal use. Portfolio, WIKI and database tools can be set up easily to accommodate knowledge exchange and collaboration.

\section{Development and Testing of a MOODLE Prototype at UEL for the Fully Online MSc BIT}

Discussion in this sub-section is further divided into three areas. The first area presents a discussion of general pre-validation activities. The other two areas are about post-validation activities that were necessary to (a) address minor conditions and recommendations offered during the validation event and to (b) initiate long term post validation development activities for MOODLE at UEL. Validation of CITE's Fully Online MSc BIT is used to highlight a variety of e-learning issues all which have helped guide development of the MOODLE-based VLE at UEL thus far.

Both the Fully Online MSc BIT and the MOODLE VLE have been developed as a result of a partnership between CITE and UELconnect. The development team made-up of CITE and UELconnect staff includes an academic, a technology advisor, a learning designer, a project manager, a number of student support professionals, and high level administrators who are in full support of the project. In addition, content writers were assigned to the project to write online content for the different modules for the fully online MSc.

\section{Pre-validation activities - March 2009 - November 2009}

Pre-validation activities for the Fully Online MSc BIT began in March 2009 when CITE administrators and academics met with professionals from UELconnect, UEL's distance learning arm. At that time various issues about contracts, scope, and possible VLE options were discussed. A second meeting was agreed between CITE's academic representative on the project and with the development team at UELconnect.

The second meeting and all subsequent monthly meetings for the project took place at UELconnect. However, a great deal of work was negotiated and completed via email communications. The project manager called frequent meetings as he felt that frequent face to face meetings, at least initially, would be of importance in pushing the project forward. While frequent meetings did hold some value for all participants, competing schedules, lack of resources, and somewhat low engagement with the project by some participants meant that various tasks went unattended and / or left undone.

During this time, validation documents for the fully online MSc were developed and work progressed on the development of a first installed MOODEL prototype.

Development work on the first prototype was completed by a Technology Advisor at UELconnect and by the CITE Academic assigned to the project. The Academic developed three initial mini-prototypes for initial review. The Technology Advisor utilised the mini-prototypes as background to the development of the first prototype found, which can be found at http://vle.uelconnect.org.uk

The current prototype represents a standard installation of MOODLE, but with customised interface and general look and feel to the application to match other applications at UEL. However, for the first prototype we only wanted the above type of application, as additional development efforts were required for the MSC programme itself, including preparation of validation documents, online content, and communication tools and other MOODLE areas relevant to the proposed programme. 
By November 2009, when the validation event was scheduled to take place, the following project deliverables were in place:

1. Validation documents: Main validation document, student handbook for the MSc, and a programme specification

2. An area was designed for the MSc in MOODLE and this included 5 Module areas for Strategic IT Management, Knowledge Management Systems, Internet IT and Law, Information Security and finally a Research Methods taught module and a Dissertations module.

3. In addition, a general programme administration area (module) was set up. Furthermore, an Educational Resources Information Centre (ERIC) was put in place to offer online resources including materials for Academic Integrity.

Within each of the module areas listed in 2 above, various resources and communication tools were put in place. These communication tools are listed below. The resources included Module Handbooks, contact information, and objectives and aims for each module. Each module was divided into 15 weeks for academic purposes, with 10 taught weeks, one week for introduction, one week for review and with additional weeks for end of the module marking and transition. Within each of the 10 taught weeks, 10 areas were offered for teaching and learning.

\section{MOODLE Communication Tools in each section (week) of each Module}

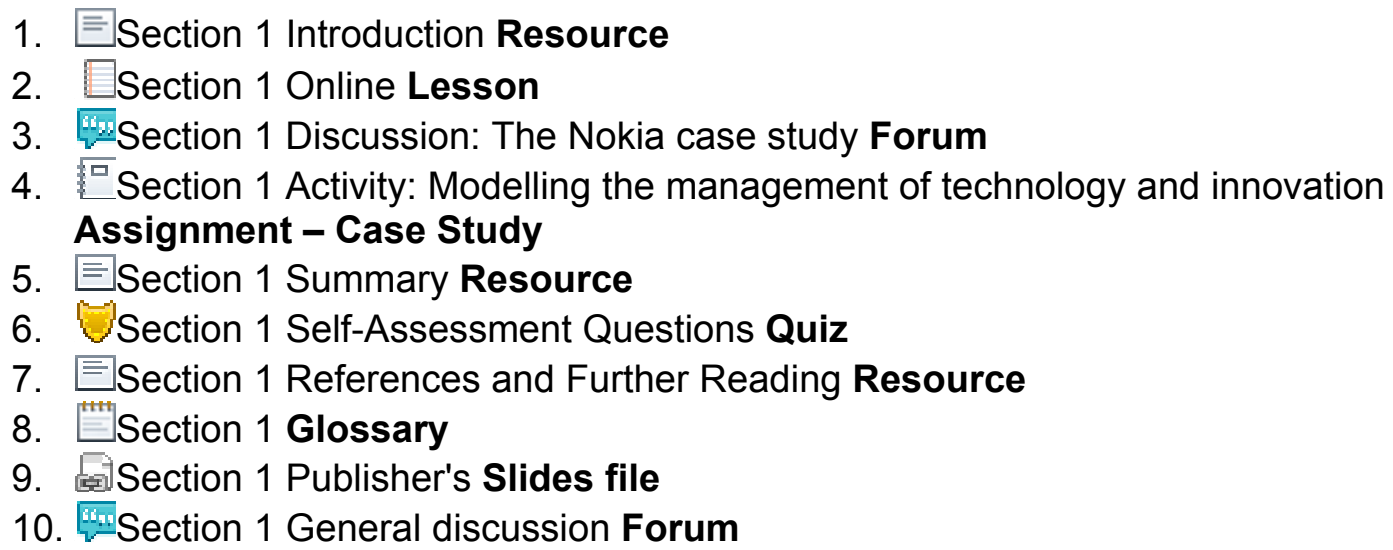

From a technical and user-centred point of view, Tutors and Module Leaders can directly change the order of the above communication tools, to delete some and add more. From an educational point of view caution should be exercised in how the above tools are managed so that the integrity of each module can be maintained.

The point is, however, that such flexibility for each modification of content and design is available in MOODLE to all interested tutors.

\section{Post Validation Event Activities - November 2009 - January 2010}

As a result of the validation event, the Fully Online MSc BIT and the MOODLE-based VLE were approved. However, three minor conditions were imposed, which amounted to modifying a couple of the assessments for clarity and streamlining the online process for MSc dissertation submissions and support. The conditions were satisfied rather quickly and a report was submitted to the University Quality Office.

There was one recommendation, however, which the Development Team opted to complete along with the conditions, even though one full year was provided to address recommendations. The 
recommendation had to do with installation of an internal email system for the MOODLE VLE for internal communications for students, tutors, modules leaders, and programme administrators.

In order to install an appropriate email system for MOODLE, the Technology Advisor and the Academic both undertook relevant research. The two main options identified were Quickmail (http://moodle.org/mod/data/view.php?d=13\&rid=764\&filter=1) and MOODLE's eMail Block (http://docs.moodle.org/en/eMail.

MOODLE's eMail Block was selected, as it offered all needed features for internal communication. It should be noted that it does not appear that the eMail Block is actively being developed. The Technology Advisor was concerned about this development inactivity. But in an email he noted that, with release of MOODLE 2.0, he hoped that backward compatibility would help take care of this issue, although such resolution was not guaranteed.

After installation of the eMail Block, five test student accounts were created as well as accounts for different members of the development team. The student accounts were created so that test emails could be sent to them from a Lecturer / Teacher account, from the Technology Assistant's account, and also from all other accounts.

All emails were safely delivered to their destinations. However, there were no attachments to the emails. So, the entire testing procedure was repeated with various sizes of attachments used. All emails with attachments over $2 \mathrm{mb}$ in size failed to arrive to their destination. This issue was easily corrected by increasing the size of attachments to $10 \mathrm{MBS}$ for testing purposes.

\section{Post-Validation Activities -Normalisation and Looking Ahead - February 2010 - Present}

Two completed modules with online content were required online in the MOODLE-based VLE for validation purposes. As part of our activities for post-validation development activities, the development team is now proceeding with development of the Research Methods Module.

The Research Methods Module and the Dissertation Module are not needed until much later. The development team, however, has made the decision to proceed with development of the Research Methods Module now as it would be of usefulness to students in their research and writing endeavours.

In addition, plans are underway to start development of video resources for all three modules.

Other future research includes a usability study which will gather student feedback on the following aspects of the VLE:

1. Theme (look and feel)

2. Functionality

3. Content

4. Server / Performance

5. Requests / Wish list

The above five topics have been added as issue areas in five separate forums on the VLE, and some information has been collected by our Technology Advisor. Feedback from students will allow us to adjust the development team's design vision of the VLE to a version that matches the needs and experiences of students as online learners.

Another study will be initiated in December 2010 after the Fully Online MSc BIT has been in operation. This will allow us to collect academic feedback on the soundness of the programme from the student's point of view and to evaluate the learning spaces and communication tools in all modules and online areas. 


\section{Conclusions}

This paper has discussed different frameworks for innovation, stressing a departure from the manufacturer-led innovation models to practitioner and user-centred frameworks and perspectives. Such departure was deemed necessary as a secondary part of the paper focused on MOODLE, open source software that relies on practitioner and user communities for its innovative development.

Practitioner and user-centred developments in innovation frameworks are part of a broader cultural turn in the information society that includes globalisation, a shift toward open source software, along with hyper-competition and a necessity to act faster in order to remain competitive. Traditional economic and systems development approaches no longer suffice for the private and public sectors and this of course includes educational institutions. The Adaptive Innovation perspective was highlighted as needed in order to collect relevant practitioner-oriented and lead usercentred qualitative responses to be used to confront changes impacting corporate and educational domains in the use and development of technology and software applications. Additional research is critical, however, in practitioner collaborations, partnerships and networks supporting development of innovative capabilities in systems.

Development of East London University's MOODLE-based VLE provided an opportunity in the paper to discuss, albeit briefly, three of Adaptive Innovation's characteristics (variety, selection, and generation) and to share some of the development team's experiences with validating a new programme and developing a new VLE for it at the same time. Additional future research is absolutely essential about the above three characteristics.

Development of a new VLE and a new fully online academic programme at the same time has been challenging to say the least, but certainly rewarding. Discussion about Adaptive Innovation was used as context to describe aspects of the VLE, including the overall design of a fully online MSC BIT and lessons learned from testing MOODLE's eMail block. Additional research is needed, however, not only about the use of MOODLE but also about the nurturing and evolution of local, context-based, socio-technical innovation systems (STIS). Future research should not simply emphasise economic aspects of rationality in pursuing innovation, but also investigate further social and cultural dimensions of innovation and the need for innovation in different contexts and as a means to empower all users and in all walks of life.

\section{References}

Chesbrough, H. (2003). Open innovation: The new imperative for creating and profiting from technology. Boston: Harvard Business School Press.

Chesbrough, H. (2006). Open business models: How to thrive in the new innovation landscape. Boston: Harvard Business School Pres.

D’Aveni, R., Canger, J. M., \& Doyle, J. J. (1993). Coping with hyper-competition: Utilizing the new 7S's framework. Academy of Management Executive, 9(3), 45-60.

D’Aveni, R. with Gunther, R. (1994). Hyper-competition: Managing the dynamics of strategic maneuvering. The Free Press.

Galambos, L. (1992). Theodore N Vail and the role of innovation in the modern Bell system. The Business History Review, 66(1), 95-126. Retrieved March 1, 2010 from http://www.jhu.edu/iaesbe/loupub_files/Theodore\%20V.pdf

Husti, I. (2009). General problems related to innovation and its potential in the Hungarian agro-food sector. Studies in Agricultural Economics, 109, 5-24. Retrieved March 3, 2010 from http://ageconsearch.umn.edu/bitstream/49189/2/No.\%20109_1.pdf 
Patterson, F. G., Jr. (2004/Rev. 2006) Life cycles for system acquisition. In A. P. Sage (Ed.), Systems engineering and management for sustainable development (pp. 82-110). Oxford, UK: Eolss Publishers, Oxford, UK, (http://www.eolss.net). Retrieved February 1, 2010 from http://www.eolss.net/ebooks/Sample\%20Chapters/C15/E1-28-01-02.pdf

Rianto, Y., Laksani, C. S., \& Prihadyanti, D. (2007) Vertical specialization as a driver for technological innovation capability building in automotive industry. Retrieved February 2, 2010 from http://asialics6.ust.hk/essay_ao/Rianto_Yan_027b_June2.pdf

Royce, W. (1970). Managing the development of large software systems. Proceedings of IEEE WESCON 26 (August): $1-9$.

Theories of Technological Change. (n.d.). Retrieved March 2, 2010 from http://kisi.deu.edu.tr/yesim.ucdogruk/ECN\%20448/ecn448_definitions.ppt

von Hippel, E. (2007). Horizontal innovation networks-by and for users. Industrial and Corporate Change 16(2), 293-315.

von Hippel, E. (1988). The sources of innovation. New York: Oxford University Press.

\section{Biography}

Dr Anastasis Petrou is a Senior Lecturer in the School of Computing, Information Technology and Engineering (CITE) at the University of East London. He currently teaches modules in the Information Systems and Multi Media Technology field where he is also involved with curriculum development and supervises student dissertations at all levels. Recently he was involved in and served as Proceedings Co-Editor for CITE's Advances in Computing and Technology (AC\&T) Conference. 